\title{
Giant chylous cyst and ileal duplication in a young adult
}

\author{
Yue $\underline{Y u}^{1}, M D$, Jin-Sheng $\underline{W u}^{1}, M D$, Zhong-Wei $\underline{K e}^{1}, M D$
}

\begin{abstract}
Alimentary tract duplications are rare congenital anomalies that usually present in childhood and occasionally in adults. They are most common in the ileum, but can occur anywhere along the alimentary tract from the mouth to the anus. We report a 24-year-old woman who presented with a giant chylous ileum cyst duplication. To our knowledge, there is only one other report of a patient with a giant chylous cyst in the literature.
\end{abstract}

Keywords: adult, alimentary tract duplications, female, ileum

\section{INTRODUCTION}

Alimentary tract duplications (ATDs) are rare congenital anomalies that usually present in childhood and occasionally in adults. ATDs are congenital anomalies that can be encountered anywhere throughout the gastrointestinal tract, from the mouth to the anus. The terminal ileum is the most frequently involved segment. ${ }^{(1)}$ Lined with intestinal mucosa, the duplication shares a common wall and mesenteric blood supply with the adjacent intestine, but usually does not communicate with the gut lumen. More than $80 \%$ of patients present before the age of two years with an acute abdomen or bowel obstruction. ${ }^{(2)}$ ATDs are frequently associated with other congenital anomalies, particularly in patients with colonic duplication. ${ }^{(3)}$ In adults, both cystic and tubular bowel duplications are rare entities. ${ }^{(4)}$

To our knowledge, only one previous study has reported a patient with a giant chylous cyst in the literature. ${ }^{(5)}$ Herein, we report a 24-year-old woman who presented with a giant chylous cyst as ileal duplication.

\section{CASE REPORT}

This report was approved by the Ethical Board of the Second Military Medical University, Shanghai, China. A 24-year-old woman presented to the general surgical department at Changhai Hospital, Shanghai, China, with a two-week history of abdominal pain. Examination revealed a distended and tender abdomen, with a large, firm, palpable mass extending from above the umbilicus into both the lower quadrants. Laboratory investigations yielded results within normal ranges. However, abdominal ultrasonography revealed a giant cyst in the abdomen. Computed tomography (CT) and magnetic resonance (MR) imaging confirmed the ultrasonographic diagnosis (Fig. 1).

Surgical intervention was decided upon. Although the cysts were initially diagnosed as mesenteric, a peristaltic mass that shared a common wall with the ileum was found during laparoscopic exploration. The exploration revealed a giant cystic

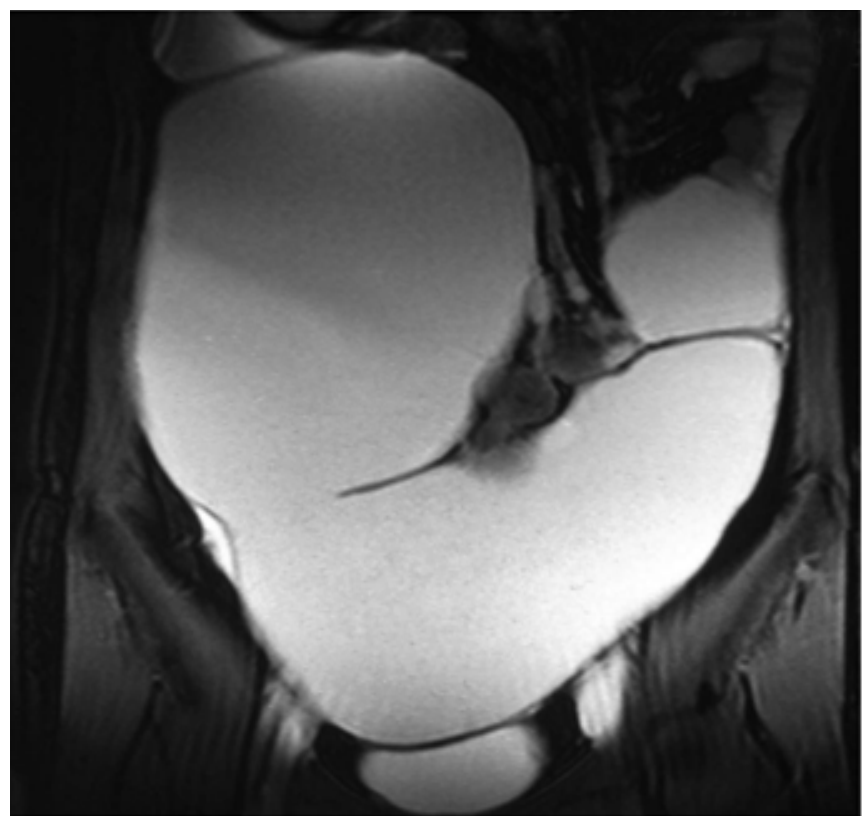

Fig. 1 MR image shows a giant cystic abdominal and pelvic mass.

mass that measured $28 \mathrm{~cm} \times 20 \mathrm{~cm}$ in size, occupying almost the entire abdominal cavity. The cyst's stalk was attached to the base of the mesentery of the terminal ileum, approximately $40 \mathrm{~cm}$ from the ileocaecal junction (Fig. 2a). The duplication was cystic and shared its muscular layer with the ileum. The cyst contained approximately 4,800 mL of thick, chylous, mucoid material. No connection was identified between the mass and the ileum. The mass and $4 \mathrm{~cm}$ of ileum were resected (Fig. 2b), and an end-to-end anastomosis was created. No further masses or anomalies were noted.

Histopathological examination revealed a multilobulated cyst that contained smooth muscle and scattered ganglion cells. The mucosal lining of the cyst was composed of intestinal epithelium and gastric mucosa. The patient's postoperative course was uneventful and she was discharged on postoperative Day 3.

${ }^{1}$ Department of General Surgery, Changhai Hospital, the Second Military Medical University, Shanghai, China

Correspondence: Prof Zhong-Wei Ke, Department of General Surgery, Changhai Hospital, the Second Military Medical University, 168 Changhai Road, Shanghai 200433, China.dr-array@hotmail.com 

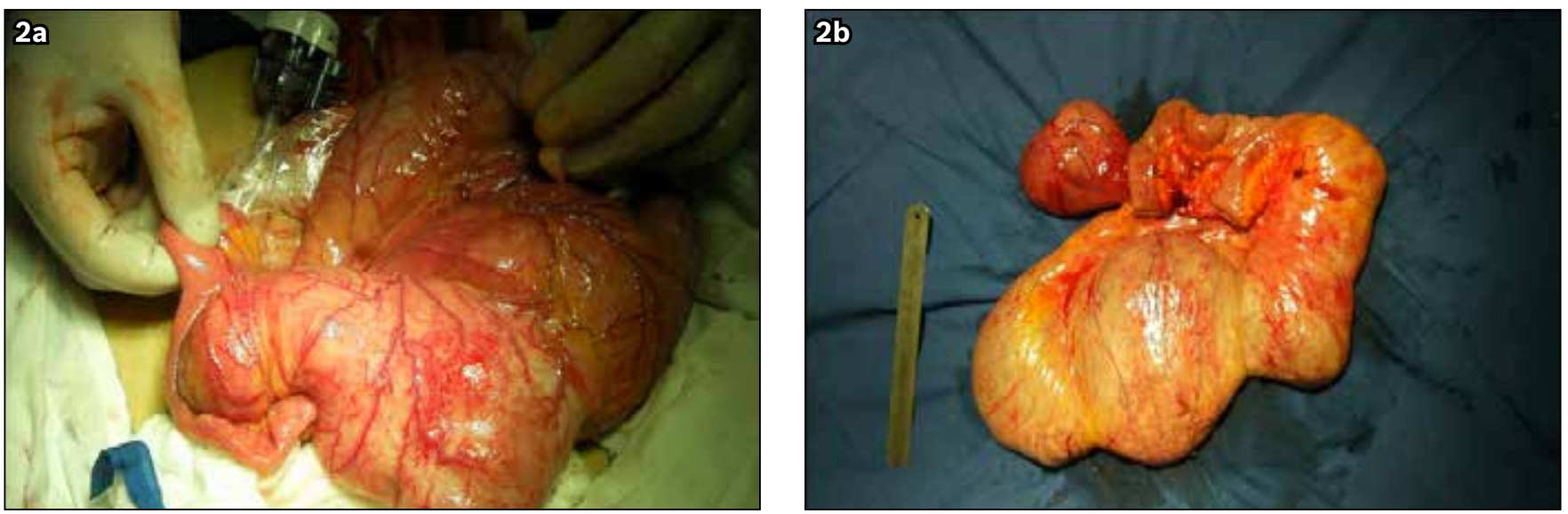

Fig. 2 Operative photographs show (a) part of the ileal duplication cyst before resection and (b) the resected duplication cyst.

\section{DISCUSSION}

A total of 28 adult patients (21 men, 7 women) with ileal duplications have been reported in the English literature, including the present study (Appendix I), with the first report published in 1884. ${ }^{(6)}$ The mean age of patients in the literature is 45.5 (range 20-81) years. The most common symptom reported was abdominal pain (20/28). Other less common symptoms include haematochezia (7/28), vomiting (6/28), nausea (5/28), diarrhoea (2/28), weight loss (3/28), routine control examination $(2 / 28)$, distension (1/28), and urinary symptoms of frequency and hesitancy (1/28). Of these, 14 patients had undergone segmental ileal resection with end-to-end anastomosis, 4 patients underwent resection of the ileal duplication with a primary anastomosis, while 3 patients required a right hemicolectomy to achieve complete resection of the duplication. A single patient required a transverse colostomy and partial jejunectomy. The ileal duplication was cystic in 17 patients and tubular in 11 patients. Malignancy in the duplication cyst was found at presentation in six patients, (including the patient with mucinous cystadenoma). Our patient, described in the present report, was found to have the largest cyst described among all of the patients published to date.

The cyst in our patient was initially diagnosed as a mesenteric chylous cyst. Mesenteric chylous cysts - also known as retroperitoneal chylomatous cysts, mesenteric lymphangiomas or chylomas of the mesentery - are extremely rare and their nonspecific clinical presentation is known to mimic ATDs. ${ }^{(7,8)}$ ATDs are defined as cystic or tubular structures found in relation to normal bowel, whose walls resemble intestine and consist of smooth muscle with alimentary tract mucosa. It is hard to differentiate ATDs from mesenteric chylous cysts based on clinical presentation and imaging examinations alone, and a definitive diagnosis is usually only made during surgery.

The clinical presentation of ATDs may vary widely. Symptoms commonly reported by patients with ATDs include vomiting, constipation, abdominal pain, obstruction, abdominal mass and haemorrhage..$^{(9,10)}$ These symptoms may be either the direct effects of distention of the duplication or caused by compression of adjacent organs. ${ }^{(11)}$ As a result of their rarity and differing modes of presentation, ATDs can be easily misdiagnosed as other disorders, including appendicitis, choledochal cyst, Meckel's diverticulum or Crohn's disease. For ATDs, it is not always possible to obtain a precise preoperative diagnosis.

Plain thoracic and abdominal radiographs, barium meal, enema, ultrasonography, endoscopic exploration, CT, MR imaging or Technetium-99m pertechnetate scintigraphy can all be used for the diagnosis of duplication cysts. ${ }^{(12,13)}$ If the ATD is a cystic bowel duplication, ultrasonography and MR imaging can be used to identify the true nature, location and extent of the lesion. ${ }^{(13,14)}$ However, for patients with tubular bowel duplications, endoscopy is the preferred diagnostic tool. ${ }^{(9)}$ Recently, CT enteroclysis has also been used to diagnose ATDs. ${ }^{(15)}$ While analysing imaging findings, clinicians should remain cognisant of the fact that duplication cyst fluid can produce elevated concentrations of tumour markers, including carcinoembryonic antigen and carbohydrate antigen CA 19.9.(16)

Surgical treatment is advocated after the diagnosis of ileal duplication in order to prevent potentially lethal complications such as perforation, volvulus, intussusception, bowel obstruction and enteric bleeding. Associated anomalies, as well as the location and size of the duplication, also influence the surgical management of the patient. Small and medium duplication cysts should be resected with a small segment of the bowel, followed by a primary anastomosis. Our analysis of the literature indicate that this procedure is performed most frequently (Appendix I). Simple excision or enucleation of an enteric cyst is possible in some patients. However, one should bear in mind that local resection of a duplication cyst can compromise the blood flow to the adjacent bowel since both share the same blood supply. ${ }^{(17)}$

Malignant transformation has been reported in the intestines of some patients diagnosed with ATDs as adults. ${ }^{(18,19)}$ The incidence of malignancy in the literature among adult patients diagnosed with ileal duplications was $6 / 28$, with one of these patients having a mucinous cystadenoma. Given the risk of malignancy, we advocate the resection of all 
duplications. The treatment outcome for surgical resection is good, with low morbidity and mortality. ${ }^{(1)}$

It is not always possible to obtain a precise preoperative diagnosis of ileal duplication cyst. Rather, a definitive diagnosis is often only reached intraoperatively. Surgical treatment should be performed to prevent potentially lethal complications in patients with ileal duplications. This report adds to the literature on the clinical variability of the presentation of ATDs and presents the second patient to be diagnosed with giant chylous cyst.

\section{REFERENCES}

1. Kuo HC, Lee $\mathrm{HC}$, Shin $\mathrm{CH}$, et al. Clinical spectrum of alimentary tract duplication in children. Acta Paediatr Taiwan 2004; 45:85-8.

2. Macpherson RI. Gastrointestinal duplications: clinical, pathologic, etiologic, and radiologic considerations. Radiographics 1993; 13:1063-80.

3. Blickman JG, Rieu PH, Buonomo C, et al. Colonic duplications: clinical presentation and radiologic features of five cases. Eur J Radiol 2006; 59:14-9.

4. Pennehouat G, Houry S, Huguier M. Sigmoid duplication in an adult. J Chir 1986; 123:169-70.

5. Sebastian JJ, Fuentes J, Boldova I, et al. Giant chylous cyst. An unusual presentation of intestinal duplication. Hepatogastroenterology 1996; 43:769-70.

6. Fitz RH. Persistent omphalo-mesenteric remains: their importance in the causation of intestinal duplication, cyst-formation, and obstruction. Am J Med Sci 1884; 88:30-57.

7. Alesen LA. Mesenteric Chylous Cysts: Report of Case. Cal West Med 1929; 30: $261-2$.
8. Lowman RM, Waters LL, Stanley HW. Mesenteric chylous cysts; associated diagnostic and surgical problems. J Int Coll Surg 1952; 18: 265-90.

9. Qasim A, Sebastian S, Johnston S, et al. Endoscopic diagnosis of a congenital ileal duplication cyst. Gastrointest Endosc 2004; 60:319-21.

10. Ogino H, Ochiai T, Nakamura N, et al. Duplication cyst of the small intestine found by double-balloon endoscopy: a case report. World J Gastroenterol 2008; 14:3924-6.

11. Fotiadis C, Genetzakis M, Papandreou I, et al. Colonic duplication in adults: report of two cases presenting with rectal bleeding. World J Gastroenterol 2005; 11:5072-4.

12. Johnson JA 3rd, Poole GV. Ileal duplications in adults. Presentation and treatment. Arch Surg 1994; 129:659-61.

13. Kusunoki N, Shimada Y, Fukumoto S, et al. Adenocarcinoma arising in a tubular duplication of the jejunum. J Gastroenterol 2003; 38:781-5.

14. Tew K, Soans BK, Millar EA. Adenocarcinoma in an ileal duplication cyst: ultrasound and computed tomography findings. Australas Radiol 2000; 44:228-31.

15. Fiori R, Viarani S, Petrella MC, et al. Intestinal duplication in an adult patient diagnosed by multidetector computed tomography enteroclysis: report of a case. Abdom Imaging 2009; 34:726-30.

16. Ikehata A, Sakuma T. Gastric duplication cyst with markedly elevated concentration of carbohydrate antigen 19-9. Am J Gastroenterol 2000; 95:842-3.

17. Bona R, Costamagna D, Gentilli S, et al. Diagnosis and surgical treatment of colonic duplication in a young woman. Tech Coloproctol 2005; 9:169.

18. Fletcher DJ, Goodfellow PB, Bardsley D. Metastatic adenocarcinoma arising from a small bowel duplication cyst. Eur J Surg Oncol 2002; 28:93-4

19. Ribaux C, Meyer P. Adenocarcinoma in an ileal duplication. Ann Pathol 1995; 15:443-5. 


\section{APPENDIX}

APPENDIX I. Summary of adult patients with ileal duplications in the English literature.

\begin{tabular}{|c|c|c|c|c|c|c|}
\hline Study (year) & Age (yrs)/ gender & Presenting features & $\begin{array}{c}\text { Surgical } \\
\text { treatment* }\end{array}$ & Form & Size $(\mathrm{cm})$ & Malignancy \\
\hline Fitz $(1884)^{(1)}$ & $65 /$ male & $\begin{array}{l}\text { Abdominal pain, } \\
\text { weight loss, diarrhoea }\end{array}$ & NA & Cystic & NA & Yes \\
\hline Nolan $(1953)^{(2)}$ & $67 /$ male & $\begin{array}{l}\text { Abdominal pain, } \\
\text { nausea, vomiting }\end{array}$ & NA & Cystic & NA & No \\
\hline Thomson et al (1954) $)^{(3)}$ & $26 /$ male & Abdominal pain & NA & Tubular & NA & No \\
\hline Micolonghi et al (1958)(4) & $31 /$ male & Haematochezia & NA & Cystic & NA & No \\
\hline Anderson et al (1962) $)^{(5)}$ & 31/male & Abdominal pain & NA & Cystic & NA & No \\
\hline Curt et al (1966) ${ }^{(6)}$ & $69 /$ male & $\begin{array}{l}\text { Abdominal pain, } \\
\text { nausea, vomiting }\end{array}$ & 3 & Tubular & $6 \times 4$ & No \\
\hline Orr et al $(1975)^{(7)}$ & $54 /$ male & $\begin{array}{l}\text { Abdominal pain, } \\
\text { nausea, vomiting }\end{array}$ & 1 & Tubular & NA & Yes \\
\hline Adair et al $(1981)^{(9)}$ & $41 /$ female & $\begin{array}{l}\text { Abdominal pain, } \\
\text { nausea, vomiting, } \\
\text { weight loss }\end{array}$ & NA & Cystic & NA & Yes \\
\hline Salameh et al (1984) $)^{(10)}$ & $30 /$ male & Haematochezia & 2 & Tubular & $11 \times 2$ & No \\
\hline Marks $(1984)^{(11)}$ & $62 /$ male & $\begin{array}{l}\text { Routine control } \\
\text { examination }\end{array}$ & 1 & Tubular & 7 & No \\
\hline Cecil et al (1990)(12) & 20/male & Abdominal pain & 1 & Cystic & $10 \times 20$ & No \\
\hline Staunton et al (1990)(13) & $31 /$ male & $\begin{array}{l}\text { Haematochezia, } \\
\text { abdominal pain }\end{array}$ & 1 & Cystic & $1.8 \times 1.8$ & No \\
\hline John et al (1994)(14) & $36 /$ female & Abdominal pain & 3 & Tubular & NA & No \\
\hline Tanabe et al (1995) (15) & $35 /$ male & Haematochezia & 1 & Tubular & $23 \times 13$ & No \\
\hline Otter et al (1996)(16) & $52 /$ male & $\begin{array}{l}\text { Urination frequency } \\
\text { and hesitancy }\end{array}$ & 1 & Cystic & $18 \times 12$ & No \\
\hline Nomura et al (2002)(18) & $61 /$ male & Abdominal pain & 2 & Cystic & $5 \times 5$ & No \\
\hline Kusunoki et al (2003)(19) & $72 /$ male & $\begin{array}{l}\text { Abdominal pain, } \\
\text { distension }\end{array}$ & 4 & Tubular & 10 & Yes \\
\hline Qasim et al (2004)(20) & $43 /$ female & $\begin{array}{l}\text { Abdominal pain, } \\
\text { vomiting }\end{array}$ & 3 & Cystic & $4 \times 3$ & No \\
\hline Simsek et al (2005) & 20/male & $\begin{array}{l}\text { Abdominal pain, } \\
\text { weight loss }\end{array}$ & 1 & Cystic & $7 \times 7$ & No \\
\hline Toth et al (2006) & $32 /$ male & Haematochezia & 1 & Cystic & $5.5 \times 2.5$ & No \\
\hline Hosseini et al (2007) $)^{(23)}$ & $54 /$ male & Haematochezia & 1 & Cystic & NA & No \\
\hline Al-Sarem et al (2007) & 23/female & Abdominal pain & 1 & Tubular & NA & No \\
\hline Tomas et al (2007) & $64 /$ female & $\begin{array}{l}\text { Routine control } \\
\text { examination }\end{array}$ & 2 & Cystic & $7.5 \times 5 \times 3$ & Yes $^{\dagger}$ \\
\hline Babu et al (2008)(26) & $59 /$ male & Abdominal pain & 1 & Tubular & $16 \times 2$ & Yes \\
\hline Ogino et al (2008) $)^{(27)}$ & $35 /$ male & $\begin{array}{l}\text { Abdominal pain, } \\
\text { haematochezia }\end{array}$ & 2 & Cystic & $2.5 \times 2$ & No \\
\hline Present study & 24/female & Abdominal pain & 1 & Cystic & $28 \times 20$ & No \\
\hline
\end{tabular}

${ }^{*}$ Surgical treatment was broadly divisible into four procedures. ${ }^{\dagger}$ Mucinous cystadenoma. 1 = segmental ileal resection with end-to end anastomosis; 2 = ileal duplication resection with primary anastomosis; 3 = right hemicolectomy with primary anastomosis; 4 = transverse colostomy and partial jejunectomy. NA: not available

\section{REFERENCES}

1. Fitz RH. Persistent omphalo-mesenteric remains: their importance in the causation of intestinal duplication, cyst-formation, and obstruction. Am J Med Sci 1884; 88:30-57.

2. Nolan JJ, Lee JG. Duplications of the alimentary tract in adults; with a report of three cases. Ann Surg 1953; 137:342-8.

3. Thomson TJ, Wilson JH, Cunningham GL. Gastrointestinal tract duplication; massive hemorrhage from ulcer. Gastroenterology 1954; 26:774-80.
4. Micolonghi T, Meissner GF. Gastric-type carcinoma arising in duplication of the small intestine. Ann Surg 1958; 147:124-7.

5. Anderson MC, Silberman WW, Shields TW. Duplications of the alimentary tract in the adult. Arch Surg 1962; 85:94-108.

6. Curt JR, Guthrie W. Duplication of the ileum presenting as appendicitis in an adult. Br J Surg 1966; 53:219-21.

7. Orr MM, Edwards AJ. Neoplastic change in duplications of the alimentary tract. Br J Surg 1975; 62:269-74. 
8. Mair WS, Abbott CR. Perforation of ileal duplication in old age. Br Med J 1976; 2:621.

9. Adair HM, Trowell JE. Squamous cell carcinoma arising in a duplication of the small bowel. J Pathol 1981; 133:25-31.

10. Salameh RN, Hausner RJ, Thomas SJ, Johnson CD. Massive hemorrhage in an ileal duplication cyst. South Med J 1984; 77:1606-7.

11. Marks PV, Stunt AE. Perforation of intestinal duplication by enteroliths after trauma. Br Med J (Clin Res Ed) 1984; 289:1744.

12. Cecil BD, Larson GM, Sewell C, Redinger RN. Abdominal pain from intestinal duplication. J Clin Gastroenterol 1990; 12:316-9.

13. Staunton DA, Jacobson AF, Thorning D, Lynch MK. Coumadin-induced gastrointestinal hemorrhage associated with an ileal duplication. J Clin Gastroenterol 1990; 12:685-9.

14. Johnson JA 3rd, Poole GV. Ileal duplications in adults. Presentation and treatment. Arch Surg 1994; 129:659-61.

15. Tanabe ID, DiTomaso A, Pinkas H, Pencev D. Massive Gl hemorrhage from an ileal duplication cyst in an adult. Am J Gastroenterol 1995; 90:504-5.

16. Otter MI, Marks CG, Cook MG. An unusual presentation of intestinal duplication with a literature review. Dig Dis Sci 1996; 41:627-9.

17. Tew K, Soans BK, Millar EA. Adenocarcinoma in an ileal duplication cyst: ultrasound and computed tomography findings. Australas Radiol 2000; 44:228-31.

18. Norman T, Shirai Y, Hatakeyama K, Nikkuni K. An adult ileal duplication cyst containing markedly elevated concentrations of carcinoembryonic antigen and carbohydrate antigen 19-9. Am J Gastroenterol 2002; 97:208-9.

19. Kusunoki N, Shimada Y, Fukumoto $S$, et al. Adenocarcinoma arising in a tubular duplication of the jejunum. J Gastroenterol 2003; 38:781-5.

20. Qasim A, Sebastian S, Johnston S, et al. Endoscopic diagnosis of a congenital ileal duplication cyst. Gastrointest Endosc 2004; 60:319-21.

21. Simsek A, Zeybek N, Yagci G, et al. Enteric and rectal duplications and duplication cysts in the adult. ANZ J Surg 2005; 75:174-6.

22. Toth $E$, Lillienau J, Ekelund $M$, et al. Ulcerated small-intestine duplication cyst: an unusual source of Gl bleeding revealed by wireless capsule endoscopy. Gastrointest Endosc 2006; 63:192-4.

23. Hosseini V, Nasseri-Moghaddam S, Soroosh AR, Hakimian MR. Photoclinic. Ileal duplication cyst. Arch Iran Med 2007; 10:417-9.

24. Al-Sarem SA, AI-Shawi JS. Ileal duplication in adults. Saudi Med J 2007; 28:1734-6.

25. Tomas D, Zovak M, Cicek S, et al. Mucinous cystadenoma arising in an isolated ileal duplication cyst. J Gastrointest Cancer 2007; 38:127-30.

26. Babu MS, Raza M. Adenocarcinoma in an ileal duplication. J Assoc Physicians India 2008; 56:119-20.

27. Ogino H, Ochiai T, Nakamura N, et al. Duplication cyst of the small intestine found by double-balloon endoscopy: a case report. World J Gastroenterol 2008; 14:3924-6. 